\title{
Low Cardiac Output in a Case of Constrictive Pericarditis with Protein-losing Enteropathy
}

\author{
Shohei Kikuchi, Nobuyuki Ohte, Kazuaki Wakami, Toshihiko Goto and Genjiro Kimura
}

\begin{abstract}
A man in his late seventies was suffering from right-sided pleural effusion and worsening leg edema. He was diagnosed with a rare case of secondary protein-losing enteropathy caused by constrictive pericarditis (CP) using technetium 99m-labeled human serum albumin abdominal scintigraphy and comprehensive Doppler echocardiography. We herein report the importance of evaluating a low cardiac output in addition to established Doppler echocardiographic findings for making a diagnosis of CP coexistent with protein-losing enteropathy.
\end{abstract}

Key words: constrictive pericarditis, protein-losing enteropathy, low cardiac output, Doppler echocardiography

(Intern Med 52: 75-79, 2013)

(DOI: 10.2169/internalmedicine.52.8811)

\section{Introduction}

Constrictive pericarditis (CP) is caused by scarring and the consequent loss of normal elasticity of the pericardium, thus resulting in enhanced interdependence of both ventricles and impaired diastolic filling. Although patients with this disease typically present with signs and symptoms of right-sided heart failure and/or low cardiac output, the symptoms are often nonspecific and develop slowly, so that making an accurate and prompt diagnosis of $\mathrm{CP}$ is sometimes difficult. Doppler echocardiography is the initial imaging modality used to make an anatomical and hemodynamic diagnosis of $\mathrm{CP}$. We herein report a rare case of $\mathrm{CP}$ coexistent with protein-losing enteropathy. In this case, Doppler echocardiography was used to make the diagnosis of $\mathrm{CP}$ along with the findings of low cardiac output and restrictive ventricular filling.

\section{Case Report}

A man in his late seventies was admitted to our hospital due to abnormal liver function tests and accumulation of a right-sided pleural effusion. He had been treated with an oral diuretic before admission. On admission, his heart rate was 80 beats/min and his blood pressure was $110 / 60 \mathrm{~mm}$ Hg. A physical examination revealed regular heart sounds without any murmurs. The patient's external jugular veins were distended. A positive hepatojuglar reflux was observed, and the liver was descended 3-4 $\mathrm{cm}$ below the right costal margin. Electrocardiogram showed a normal sinus rhythm with low voltage in the limb leads. Chest radiograph revealed a right-sided pleural effusion without pulmonary congestion. The laboratory findings are shown in Table. The patient's serum albumin level was found to have decreased, the serum creatinine level was in the normal range and no urinary protein was detected. Abdominal computed tomography did not show any findings of liver cirrhosis.

After admission, the patient received the intravenous injection of furosemide to treat the pleural effusion and leg edema, and his blood pressure remarkably decreased to 60 $\mathrm{mmHg}$ in systole; however, after discontinuation of furosemide, the patient's blood pressure recovered to the original level. Fluid obtained with thoracentesis exhibited a transudate nature. A low serum albumin concentration with an absence of nephrotic syndrome, liver cirrhosis or malnutrition suggested a diagnosis of protein-losing enteropathy. Technetium 99m-labeled human serum albumin-diethylenetriaminepenta-acetic acid ( $\left.{ }^{99 \mathrm{~m}} \mathrm{Tc}-\mathrm{HSAD}\right)$ scintigraphy revealed an accumulation of radionuclide in the intestines in 
Table. Laboratory Data at Admission

\begin{tabular}{|c|c|c|c|}
\hline Characteristic & Value & Characteristic & Value \\
\hline White blood cell count (per $\mathrm{mm}^{3}$ ) & 5,000 & Blood urea nitrogen $(\mathrm{mg} / \mathrm{dL})$ & 13 \\
\hline Hemoglobin (g/dL) & 13.7 & Total cholesterol (mg/dL) & 165 \\
\hline Hematocrit (\%) & 43.1 & Triglyceride (mg/dL) & 77 \\
\hline Platelet count $\left(\times 10^{4}\right.$ per $\left.\mathrm{mm}^{3}\right)$ & 22.2 & Glucose (mg/dL) & 291 \\
\hline Total protein $(\mathrm{g} / \mathrm{dL})$ & 4.7 & Serum sodium $(\mathrm{mEq} / \mathrm{L})$ & 140 \\
\hline Serum albumin $(\mathrm{g} / \mathrm{dL})$ & 2.4 & Serum potassium $(\mathrm{mEq} / \mathrm{L})$ & 4.1 \\
\hline Aspartate aminotransferase (U/L) & 39 & $\begin{array}{l}\text { Brain natriuretic peptide } \\
(\mathrm{pg} / \mathrm{mL})\end{array}$ & 92.0 \\
\hline Alanine aminotransferase (U/L) & 23 & $\begin{array}{l}\text { Thyroid stimulation hormone } \\
(\mu \mathrm{IU} / \mathrm{mL})\end{array}$ & 12.1 \\
\hline Alkaline phosphatase (U/L) & 411 & Free thyroxine $(\mathrm{mg} / \mathrm{dL})$ & 0.82 \\
\hline Lactate dehydrogenase (U/L) & 204 & Free triiodothyronine $(\mathrm{pg} / \mathrm{mL})$ & 2.94 \\
\hline Total bilirubin $(\mathrm{mg} / \mathrm{dL})$ & 0.5 & Spot urinary protein & $(-)$ \\
\hline Creatinine (mg/dL) & 0.7 & & \\
\hline
\end{tabular}

the right side of the abdomen (Fig. 1A). Therefore, the hypoalbuminemia was ultimately diagnosed to be the result of protein-losing enteropathy. With regard to the differential diagnosis of protein-losing enteropathy, gastrointestinal amyloidosis and malignant lymphoma of the intestines were both proven to be negative on endoscopic and histological examinations.

Contrast-enhanced cardiac computed tomography disclosed a thickened pericardium (Fig. 1B). Two-dimensional echocardiography also showed thickened pericardium around the heart (Fig. 1C), a normal left ventricular (LV) cavity size (end-diastolic dimension: $36 \mathrm{~mm}$ and end-systolic dimension: $25 \mathrm{~mm}$ ) and a normal wall thickness as well as a preserved LV ejection fraction (61\%). Both the right atrium (RA) and the left atrium (LA) were mildly distended (Fig. 1D). The maximum diameter of the LA at end-systole in the apical four-chamber view was $43 \mathrm{~mm}$. The calculated LA volume and the LA volume indexed to the patient's body surface area at end-systole were $60.5 \mathrm{~mL}$ and $39 \mathrm{~mL} /$ $\mathrm{m}^{2}$, respectively. The peak early to peak late velocity ratio (E/A) in transmitral flow was $>1.0$, and the early diastolic mitral annular velocity at the septal corner was exaggerated $(12.6 \mathrm{~cm} / \mathrm{s})$ (Fig. 2A, 2B). Significant decreases in early diastolic transmitral flow velocity and significant increases in the early diastolic transtricuspid flow velocity during inspiration were observed (Fig. 2C). The alteration of the early diastolic transmitral flow velocity during respiration was $29 \%$ and that of early diastolic transtricuspid flow velocity was $30 \%$. The inferior vena cava was found to be distended $(19 \mathrm{~mm})$ with a poor respiratory change. The velocity-time integral at the LV outflow tract obtained with pulsed Doppler echocardiography was low $(11.5 \mathrm{~cm})$ (Fig. 2D). The cardiac output calculated from the velocity-time integral at the LV outflow tract and the diameter of the LV outflow tract $(3.04 \mathrm{~L} / \mathrm{min})$ and cardiac index calculated from the cardiac output and the body surface area $\left(1.96 \mathrm{~L} / \mathrm{min} / \mathrm{m}^{2}\right)$ suggested a low cardiac output status. The pressure gradient at the tricuspid valve calculated from the tricuspid regurgitant flow velocity was in the normal range $(21 \mathrm{~mm} \mathrm{Hg})$. There were no signs of pulmonary hypertension. Based on these findings, a diagnosis of $\mathrm{CP}$ was suspected. Simultaneous pressure recording of the right and left ventricles during cardiac catheterization showed equalization of the end-diastolic pressures with so-called dip and plateau patterns (Fig. 3). Therefore, the diagnosis of CP was confirmed anatomically and hemodynamically, and a diagnosis of protein-losing enteropathy was considered secondary to CP.

Pericardiectomy was performed and the results of a histological examination of the pericardium were compatible with a diagnosis of CP. After surgery, the value of serum albumin rose to $4.1 \mathrm{~g} / \mathrm{dL}$, and the patient's leg edema and pleural effusion completely disappeared. Postoperative Doppler echocardiography showed ordinary respiratory alterations of the peak early diastolic transmitral and transtricuspid flow velocities. The velocity-time integral at the LV outflow tract increased to $16.0 \mathrm{~cm}$, and the cardiac output and cardiac index increased to $4.43 \mathrm{~L} / \mathrm{min}$ and $2.86 \mathrm{~L} / \mathrm{min} / \mathrm{m}^{2}$, respectively.

\section{Discussion}

Protein-losing enteropathies are characterized by an excessive loss of serum proteins into the gastrointestinal tract, resulting in hypoalbuminemia, edema, ascites and pleural effusion. Dilated intestinal lymphatic ducts are observed not only in patients with primary lymphangiectasia, but also in those with secondary causes of impaired lymphatic flow. Cardiac diseases such as CP, cardiac amyloidosis and pul- 

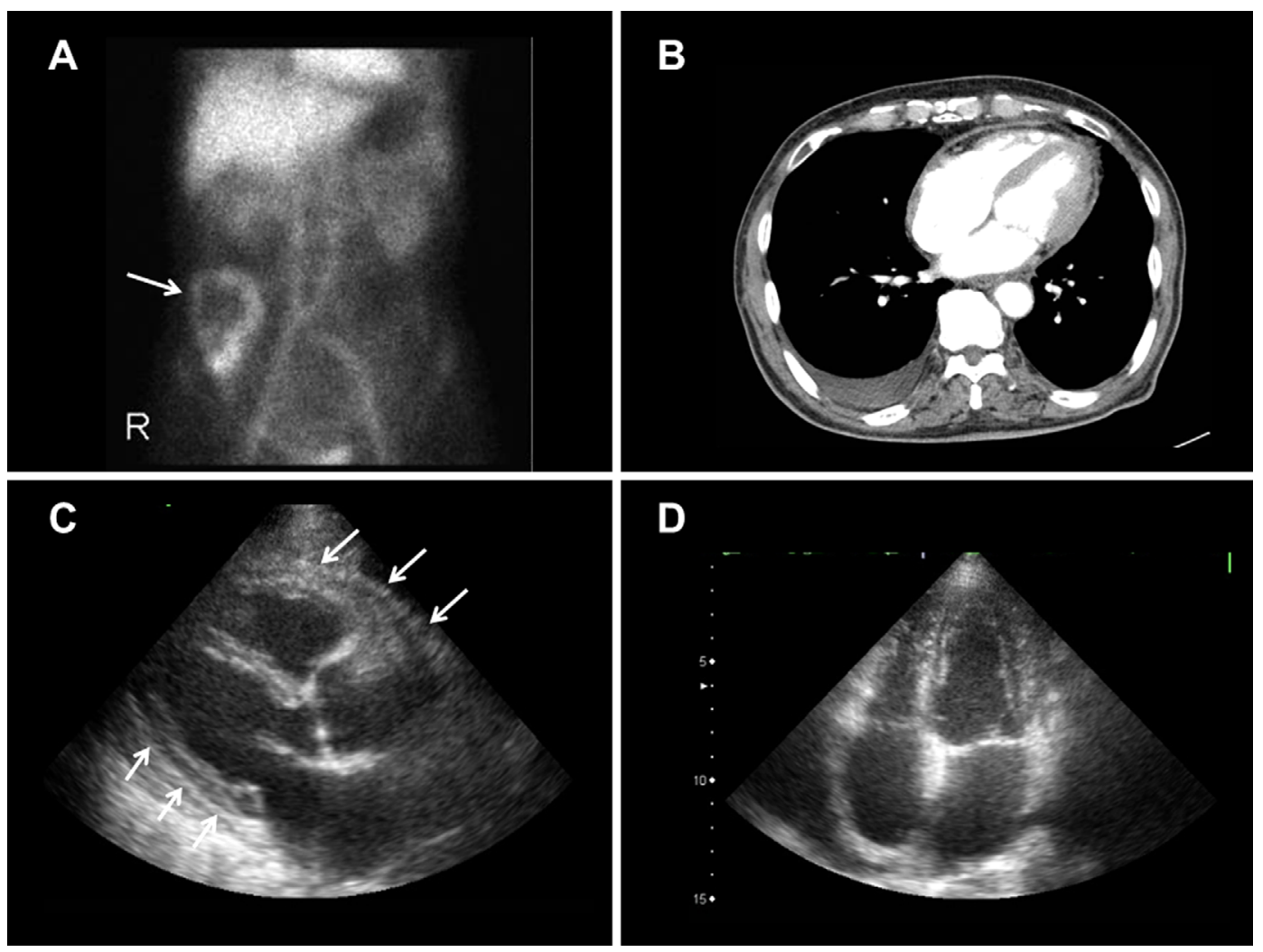

Figure 1. A. A representative image of technetium 99m-labeled human serum albumin-diethylenetriaminepenta-acetic acid $\left({ }^{99}\right.$ mc-HSAD) abdominal scintigraphy. ${ }^{99 m}$ Tc-HSAD was found to be accumulated in the intestines in the right side of the abdomen (arrow). Serum albumin was lost into the intestinal lumen. B. Contrast-enhanced cardiac computed tomography. An apparently thickened pericardium and a right-sided pleural effusion were observed. C. Two-dimensional echocardiography. Pericardial thickening around the heart was observed (arrows). D. An apical four-chamber view of the heart at end-systole. The right and left atria were mildly distended.

monary hypertension are the most common causes of secondary intestinal lymphangiectasia (1). Several reports have described the existence of an association between proteinlosing enteropathy and CP (2-4). It has been demonstrated that moderate pericardial constriction not resulting in discernible pressure abnormalities in the right heart can be associated with protein-losing enteropathy and eventually cause hypoproteinemic peripheral edema (4). In our patient, the filling pressures of the right and left ventricles were elevated, and the observed peripheral edema seemed to be the result of the elevated venous pressure and hypoproteinemia.

One of the typical anatomical changes observed in $\mathrm{CP}$ is the enlargement of both atria. The LA size and volume index were larger in this patient compared with those reported in age-matched healthy Japanese men $(3.6 \pm 0.6 \mathrm{~cm}$ and $24 \pm 9$ $\mathrm{mL} / \mathrm{m}^{2}$, respectively) (5).

Typical hemodynamic changes in patients with $\mathrm{CP}$ are often reflected in Doppler echocardiographic findings. In patients with $\mathrm{CP}$, transmitral flow velocity waveforms generally show a pseudonormalized or restrictive pattern that represents impaired LV filling and elevated LV filling pressure. Dissociation of the intracardiac pressure from the intrathoracic pressure and enhanced interdependence between both ventricles are responsible for remarkable changes in transmi- tral and transtricuspid flow velocity waveforms during diastole caused by the respiratory phase. A previous report showed that significant respiratory variations in the peak early diastolic transmitral flow velocity, peak early diastolic transtricuspid flow velocity and hepatic vein flow velocity had high sensitivities and moderate specificities for the diagnosis of CP (6). The respiratory variations in the peak early diastolic transmitral and peak early diastolic transtricuspid flow velocities observed in this patient met the criteria for the diagnosis of CP. As the LV diastolic property in the longitudinal direction is relatively preserved in patients with $\mathrm{CP}$, as noticed in this patient, the early diastolic mitral annular velocity along the LV long-axis is normal or rather exaggerated $(5,6)$. This value is useful for distinguishing patients with constrictive pericarditis from those with restrictive cardiomyopathy (7).

Although the LV systolic function is usually preserved in this category of patients, deteriorated LV filling is related to decreases in stroke volume. Little and Freeman (8), in their widely acknowledged review paper, reported that patients with pericardial constriction typically present with manifestations of elevated systemic venous pressure and low cardiac output. Low cardiac output in CP patients is a crucial finding, although most cardiologists may focus more on elevated 

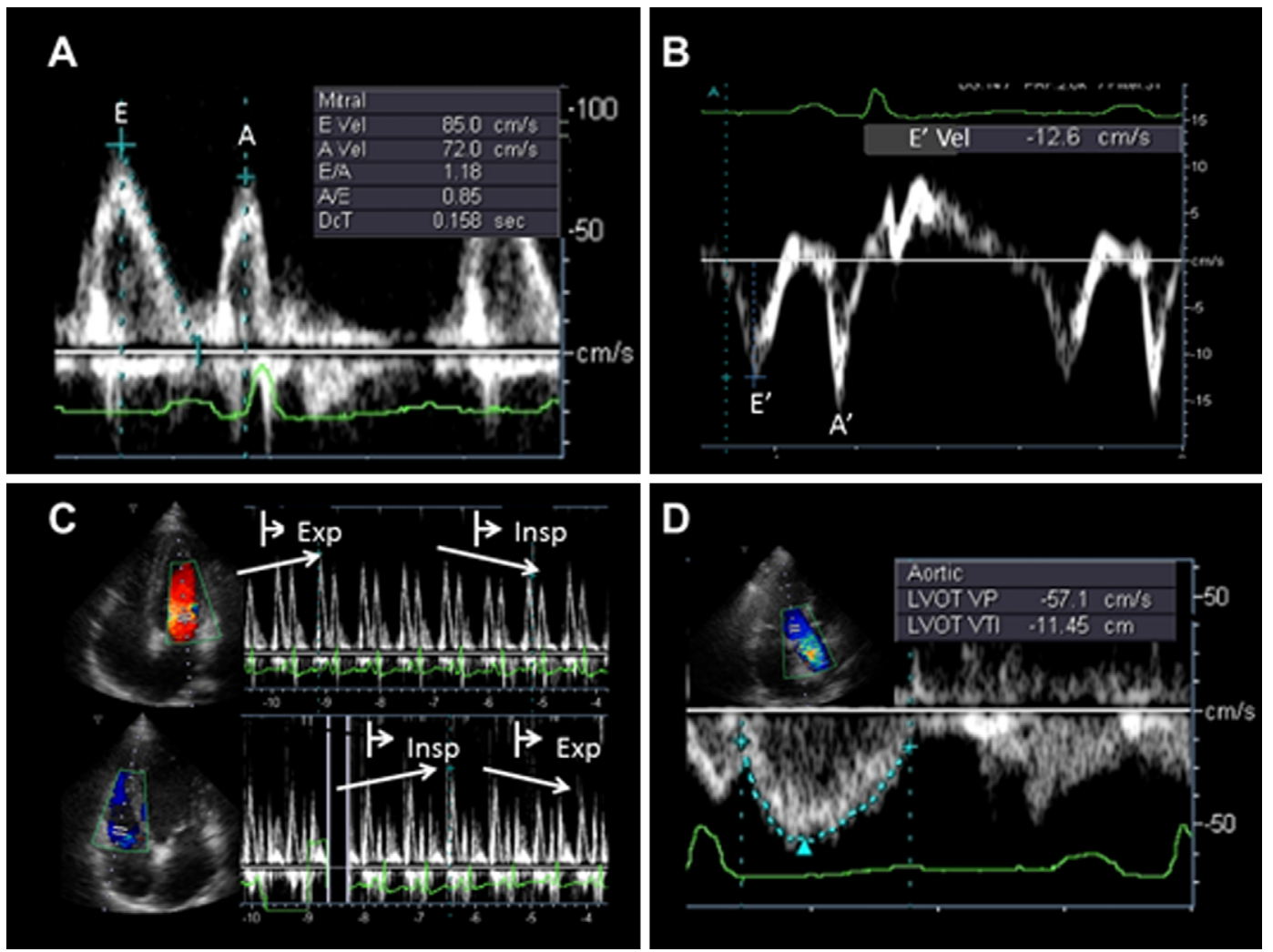

Figure 2. A. Transmitral flow velocity waveforms on pulsed Doppler echocardiography. A pseudonormalized pattern was observed. B. The mitral annular velocity at the septal corner on pulsed Doppler tissue velocity imaging. The mitral annular velocity during early diastole was relatively fast. C. A pulsed Doppler echocardiographic assessment of the effects of respiratory phase on the transmitral and transtricuspid flow velocity waveforms in diastole. Decreases in the early diastolic transmitral flow velocity during inspiration (upper) and increases in the early diastolic transtricuspid flow velocity during inspiration (bottom) were observed. D. Flow velocity waveforms obtained at the left ventricular outflow tract. The time-velocity integral during systole was low for an adult.

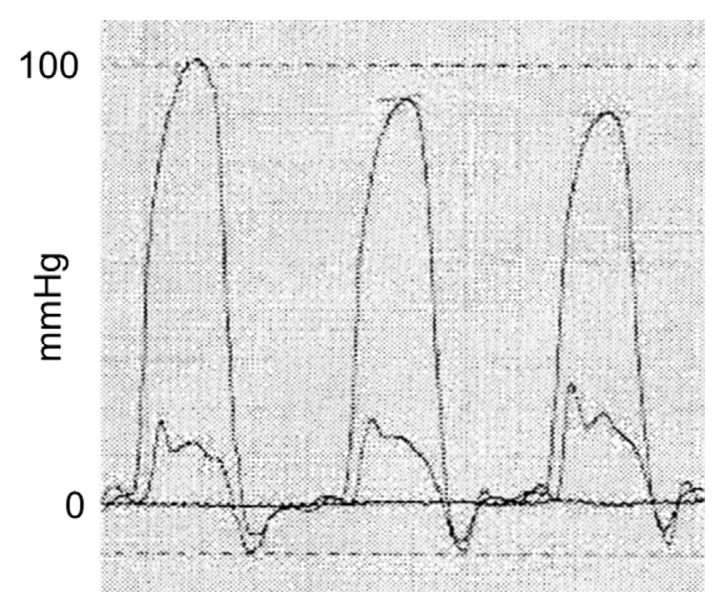

Figure 3. Simultaneous pressure recordings in the left and right ventricles during cardiac catheterization. Similar values in the left and right ventricular end-diastolic pressures with so-called dip and plateau patterns were observed.

venous pressure than low cardiac output when making a diagnosis of CP. In this patient, the reduction of effective circulating intravascular fluid volume caused by hypoproteine- mia may have also been related to low stroke volume, which was reflected in the small value of the velocity-time integral at the LV outflow tract measured on pulsed Doppler echocardiography. If a patient shows an inappropriately small value of the velocity-time integral at the LV outflow tract compared with his or her LV systolic function, CP should be considered as a diagnosis.

The authors state that they have no Conflict of Interest (COI).

\section{References}

1. Gracey M, Anderson CM. Intestinal lymphangiectasia and other causes of protein-losing gastroenteropaties. In: Paediatric Gastroenterology and Hepatology. Gracey M, Burke V, Eds. Blackwell Scientific Pub, London, 1993: 439-440.

2. Nikolaidis N, Tziomalos K, Giouleme O, et al. Protein-losing enteropathy as the principal manifestation of constrictive pericarditis. J Gen Intern Med 20: C5-C7, 2005.

3. Meijers BK, Schalla S, Eerens F, et al. Protein-losing enteropathy in association with constrictive pericarditis. Int J Cardiovasc Imaging 22: 389-392, 2006.

4. Müller C, Globits S, Glogar D, Klepetko W, Knoflach P. Constric- 
tive pericarditis without typical haemodynamic changes as a cause of oedema formation due to protein-losing enteropathy. Eur Heart J 12: 1140-1143, 1991.

5. Daimon M, Watanabe $H$, Abe $Y$, et al. Normal values of echocardiographic parameters in relation to age in a healthy Japanese population: the JAMP study. Circ J 72: 1859-1866, 2008.

6. Dal-Bianco JP, Sengupta PP, Mookadam F, Chandrasekaran K, Tajik AJ, Khandheria BK. Role of echocardiography in the diagnosis of constrictive pericarditis. J Am Soc Echocardiogr 22: 24-33,
2009.

7. Garcia MJ, Rodriguez L, Ares M, Griffin BP, Thomas JD, Klein AL. Differentiation of constrictive pericarditis from restrictive cardiomyopathy: assessment of left ventricular diastolic velocities in longitudinal axis by Doppler tissue imaging. J Am Coll Cardiol 27: 108-114, 1996.

8. Little WC, Freeman GL. Pericardial disease. Circulation 113: 1622-1632, 2006.

\section{(C) 2013 The Japanese Society of Internal Medicine http://www.naika.or.jp/imonline/index.html}

